\title{
The Italian Experience of the Covenant of Mayors: A Territorial Evaluation
}

\author{
Luigi Santopietro *(D) and Francesco Scorza (D)
}

check for updates

Citation: Santopietro, L.; Scorza, F. The Italian Experience of the Covenant of Mayors: A Territorial Evaluation. Sustainability 2021, 13, 1289. https://doi.org/10.3390/ su13031289

\section{Academic Editor:}

Wadim Strielkowski

Received: 25 November 2020

Accepted: 21 January 2021

Published: 26 January 2021

Publisher's Note: MDPI stays neutral with regard to jurisdictional claims in published maps and institutional affiliations.

Copyright: (c) 2021 by the authors. Licensee MDPI, Basel, Switzerland. This article is an open access article distributed under the terms and conditions of the Creative Commons Attribution (CC BY) license (https:// creativecommons.org/licenses/by/ $4.0 /)$.
Laboratory of Urban and Regional Systems Engineering (LISUT), School of Engineering, University of Basilicata, 85100 Potenza, Italy; francesco.scorza@unibas.it

* Correspondence: lgusnt@gmail.com; Tel.: +39-346-515-6120

\begin{abstract}
European climate policy, since the 1990s, has developed incrementally and supported programs, plans and actions for sustainable, clean and secure energy. Additionally, climate-change adaptation issues have been tackled through Mayors Adapt since 2016. The Covenant of Mayors (CoM), a volunteer movement of local administrators established in 2008 , set a target of a $20 \%$ reduction in $\mathrm{CO}_{2}$ emissions by 2020. The $\mathrm{CoM}$ has launched a new season on energy planning in Europe based on Sustainable Energy Action Plans (SEAPs), defining actions for selected intervention sectors. The aim of the work was to evaluate the state of the Italian CoM signatories, assessing the results achieved in terms of the Municipalities involved (CoM signatories), the SEAPs developed and the Monitoring Reports submitted. Specifically, the analysis of the Monitoring Reports data represents a relevant step needed in order to formulate some critical appraisals concerning the performance level of CoM adoption at a national scale, in terms of the commitment levels, goals achieved and actions completed or in progress. The paper also compares national figures with a regional detailed survey developed for the Basilicata Region. It represents a benchmark useful for interpreting the general results derived from the CoM official data and a marker for pointing out suggestions for improving the Global Covenant of Mayors for Climate and Energy (GCoM) adoption procedures.
\end{abstract}

Keywords: SEAP; Covenant of Mayors; energy plans; voluntary-based planning; European policies; climate change; $\mathrm{CO}_{2}$ emission reduction

\section{Introduction}

The Covenant of Mayors (CoM) was launched in 2008 in Europe fostering an ambition to gather local governments voluntarily and committed to achieving and exceeding the EU climate and energy targets [1]. In October 2015, the new Covenant of Mayors for Climate \& Energy was launched. Its goals were defined with cities through a consultation process and are ambitious and broad-ranging: signatory cities are now committed to actively supporting the implementation of the EU 40\% greenhouse gas (GHG)-reduction target by 2030 and agree to adopt an integrated approach to climate change mitigation and adaptation and ensure access to secure, sustainable and affordable energy for all. In the same year, the EU signed the Paris Agreement [2]. This global strategy integrates energy and climate policies including the so-called 20/20/20 targets [3], namely, the reduction of carbon dioxide $\left(\mathrm{CO}_{2}\right)$ emissions by $20 \%$, an increase in the market share of renewable energy to $20 \%$, and a $20 \%$ increase in energy efficiency. In June 2016, the Covenant of Mayors entered a relevant new phase of its history, joining with another city initiative, the Compact of Mayors.

The Compact of Mayors is an agreement between city networks-and by their members - to adopt a transparent and supportive approach to reducing city-level emissions, to reducing vulnerability and to enhancing resilience to climate change [4-6], in a consistent and complementary manner with respect to national-level climate protection efforts. The Compact of Mayors builds on the ongoing efforts of the Mayors-i.e., an elected Senior representative of a city and/or the City Council (if this is required for a 
commitment) that represents a city administration-and may agree to such a commitment that increasingly sets ambitious, voluntary city climate commitments (intended to align with significant and internationally recognized approaches) or targets for greenhouse gas (GHG) emission reduction and to address climate risk [7]; report on progress towards achieving those targets by meeting robust, rigorous and consistent reporting standards (as established through City Networks); and make that information publicly available by reporting through a recognized city platform, such as the carbon Cities Climate Registry, CDP Cities.

The resulting "Global Covenant of Mayors for Climate and Energy" (GCoM) is currently the largest movement of local governments committed to going beyond their own national climate and energy objectives. More than 10,000 cities committed to the GCoM have a major collective potential, and if this is fully realized, these city and local government actions could account for 2.3 billion tons of $\mathrm{CO}_{2} \mathrm{eq}$ annual emissions reduction in 2030, matching yearly passenger road emissions from the U.S., China, France, Mexico, Russia and Argentina combined.

With an annual emissions reduction expected to reach 4.2 billion tons of $\mathrm{CO}_{2} \mathrm{eq}$ in 2050, GCoM cities are showcasing the massive urban opportunity that national governments can harness to accelerate action and progress towards the Paris Agreement goals-simultaneously safeguarding the health and prosperity of their citizens.

Fully in line with the UN Sustainable Development Goals such as affordable and clean energy, climate action and sustainable cities/communities [8,9], the GCoM will tackle three key issues:

- Climate change mitigation;

- Adaptation to the adverse effects of climate change;

- Universal access to secure, clean and affordable energy.

In October 2020, the Covenant of Mayors for Europe counted 10,355 signatories; each signatory adopted a Sustainable Energy Action Plan (SEAP), and all of them are able to develop a Sustainable Energy and Climate Action Plan (SECAP) with new ambitious goals: the EU 40\% greenhouse gas-reduction target by 2030 and the adoption of a joint approach to tackling the mitigation of and adaptation to climate change [10,11].

Such widespread commitment of local authorities in pursuing performance objectives under "green responsibility" in urban and territorial management represents a relevant result from a double perspective:

- The extensive pervasiveness of climate and sustainable goals in local communities as a result of global movements [12];

- The success of voluntary-based planning processes for tackling current issues in urban and territorial planning compared with traditional planning practices and tools that are considered to be mainly inadequate for adapting to new intervention domains and practices (also see [13]).

Apart from the extensive success of the CoM initiative, it is relevant to underline the ineffective components that arise if the focus moves towards the second stage of implementation: the monitoring reporting phase.

The first term of the CoM is 2020, regarding the $\mathrm{CO}_{2}$ commitments taken on by the signatories, and it was chosen as a reference point for checking the number of CoM signatories and SEAPs developed, choosing Italy as a study area.

Before carrying out an assessment of the CoM implementation, we considered some authors [13-15] who have reported the status and the progress of the response of European Countries and cities in developing action plans addressing climate change issues. In this domain, Reckien et al. [13] have suggested a classification of local climate plans, and found three types of standalone local climate plans:

- $\quad$ Type A1, autonomously produced plans;

- $\quad$ Type A2, plans produced to comply with national regulations;

- $\quad$ Type A3, plans developed for international climate networks. 
This classification is based on the analyses of the local climate plans in 885 cities across the 28 EU countries screened through an Urban Audit, and does not allow reporting a comprehensive assessment of the CoM signatories or any city with a local climate plan for every EU country. However, this work represents an assessment of the associations between European climate planning development and the major reference framework policies such as the EU CoM, the C40 Cities Climate Leadership Group (C40), the Local Governments for Sustainability (ICLEI), and the United Cities and Local Governments (UCLG).

Among the different approaches, the case of Denmark represents an example of national legislation (LBK no. 523 [16] and LOV no. 716 [17]) driving the Municipalities to include climate change adaptation in Municipal spatial plans, a requirement integrated into Danish planning law since February 2018. Moreover, Denmark is among the few European countries with a Ministry of Climate [18], which was created in the wake of the UNFCCC Conference in Copenhagen in 2009 [19].

Differently, the analysis produced by Aguilar et al. [14] refers to the identification of Local Adaptation Strategies (LAS), which include all adaptation strategies and plans at a Municipal level. Municipalities are intended as political units with local governments, such as cities, towns and villages, which also encompass small settlements and their rural areas, including metropolitan areas and small counties.

They recognize 147 LAS that cover the 28 European Union countries and the three European Free Trade Association (EFTA) countries: Iceland, Liechtenstein and Norway. In this entirety of practices classified as LAS, it is not possible to recognize aggregated or national features; the useful outcomes of the research are mainly identified in the following features:

i. Most LAS have been developed at a local level (Municipalities, interest groups and private organizations) under the support of governmental stakeholders (i.e., State Administrations, Regional Authorities, etc.). The main barrier for the implementation of adaptation plans is a lack of financial and human resources, highlighting the dependence on external financial support for local adaptation.

ii. In specific geographical areas, it is possible to recognize some push factors that started the process of LAS development, such as the following:

Coastal areas and disaster risk reduction for Northern regions, related to the vulnerabilities and hazard risks of territories. In this group, the Municipalities of Malmö and Copenhagen can be considered as examples. Malmö introduced the concept of sustainable urban drainage as early as the late 1980s. This was mainly a result of Malmo Water's active interest in finding new technical solutions for detaining peak flows in the urban runoff from new settlements. In the late 1990s, the city of Malmö drew up a policy document describing the general principles for managing storm water in a new, sustainable manner [20]. Copenhagen, after the intense storm on the 2nd of July 2011, developed its Climate Adaptation Plan suggesting two measures to mitigate flooding in the case of extreme events: a long-term plan changing the current combined sewer network to a separate network, and using public surfaces with low sensitivity (e.g., parks, sport fields and open spaces) for the temporary storage of storm water.

Business and services for Eastern Europe, related to prioritizing the importance of managing commercial risks, in addition to climate vulnerability and hazard risks. In this group, examples are Bratislava and Budapest. Bratislava, in its plan, has chosen to protect the most vulnerable groups of the urban population (the elderly, the homeless, children up to the age of 6 years, pensioners living along, etc.); minimize the carbon footprint of the city through housing/building, transport and waste treatment; and implement green and soft adaptation measures to maximize the use of rainwater and green infrastructure. Budapest has developed an integrated urban development strategy, implementing, for 2030, a long-term urban development concept. In this framework, a primary goal set is to increase the efficiency of use, to increase the proportion of renewables and to reduce greenhouse gas emissions. In addition, it is important to decrease the energy loss that occurs during the usage and transfer of resources, as well as to reduce energy demand. 
Adaptation for tourism, energy and agriculture for Southern Europe, related to prioritizing the import tourism sector through the improvement of energy efficiency and reduction of GHG emissions. In this group, examples are Barcelona and Padua. Barcelona's PECQ (Energy, Climate Change and Air Quality Plan of Barcelona) is a plan promoted by Barcelona's City Council aimed at providing the Public Administration with strategic tools in order to improve citizens' health and that of the Planet by increasing energy efficiency and reducing greenhouse gas emissions together with other local-effect pollutants. Padua has articulated its methodology for the Adaptation Plan in six fundamental phases, through which the Municipality has identified, in order to adapt the urban areas to the effects of climate change, vulnerable areas, with the aim of studying the type of shock and then increasing the capacity to react to shocks generated by ongoing climate change.

As a reference for this study, we selected the approach conveyed by Coelho [15] and applied in the case of the Portuguese experience of CoM implementation. This research assessed the local community reaction to SEAPs in Portugal by investigating 124 Portuguese Municipalities in terms of emission reduction measures included in the SEAP and Baseline Emission Inventory. A relevant indicator is the percentage of the resident population covered by the SEAP: major cities contribute more to this appraisal, while $65 \%$ of the total Municipalities cannot be considered to be under any energy planning regulation.

The aim of this work was to describe a critical assessment of the Italian experience in the implementation of the Covenant of Mayors, referring to the first deadline set to 2020 for reaching targets [3]. In the Italian case, different approaches to CoM implementation are observable in the main territorial sub-areas: the North, Centre and South of Italy. This study formulated hypotheses concerning the causes of such differences and describes comprehensive figures deriving from the classification of the CoM intervention priorities. A regional focus is also presented in order to demonstrate the lack of data in the official CoM Database (DB) and to discuss the theory concerning the local municipality approach towards sustainable energy planning as an alternative to institutional urban planning [21]. Our analysis took into consideration the SEAP Monitoring Reports. Through the elaboration of such information, the "state of the art" of CoM implementation is described (Section 1)

In Section 2, a spatial assessment of the Italian signatories and the corresponding SEAPs developed is presented according to the Nomenclature of Territorial Units for Statistics (NUTS) 1. The investigation of the intervention sector occurrences represents a second elaboration considered to be useful for enabling a deeper understanding of the differences in approaches promoted through the development of the SEAPs in different areas.

Section 3 is structured in three parts:

- The first provides an assessment of the Italian CoM signatories compared to the resident population per NUTS- 1 area and an evaluation of the CoM sector occurrences among the submitted SEAPs.

- The second part looks at the Monitoring Reports (MRs) as a critical stage of COM implementation. From the perspective of the authors, they are a fundamental step in producing information on the overall CoM impact at different scales. The MRs are related to a quantitative evaluation of the implemented actions and account for the differences between intervention sectors included "a priori" in the SEAP and the effective sectors implemented at the end of the monitoring period (in other words, the adaptation capacity of the SEAP and the local context feasibility of investments).

- The third part provides a detailed check for the Basilicata Region in order to obtain local detailed information on the status of the monitoring phase in the implementation of the SEAPs. Such analysis was oriented towards revealing some information missing from the CoM open-database and testing the hypothesis concerning the criticalities in the local procedures of the SEAPs' management.

Sections 4 and 5 discuss the main results and outcomes, and on the basis of the regional focus, we discuss the critical tendency, on behalf of the Italian Municipalities, to prefer voluntary planning procedures ("EU CoM-like") to the traditional urban planning 
practices according to regional and national laws. This interesting outcome allowed discussing a critical position concerning the effectiveness of voluntary planning instruments vs. institutional planning tools.

The Conclusions explain the main results deriving from the investigated data from the CoM DB, the relevant CoM signatories, the resident population under the SEAP Municipalities, the MRs submitted and the occurrences of sectors among the Italian signatories. Additionally, they take into account the forthcoming season of GCoM characterized by the challenge of climate change, with the development of mitigation/adaptation strategies at an urban scale and the ambitious $40 \%$ reduction of $\mathrm{CO}_{2}$ emissions by 2030 .

\section{Materials and Methods}

The data collected were derived from the official website of the Covenant of Mayors for Climate \& Energy Europe [22]. On the website, all the Action Plans submitted by the Covenant signatories, either already accepted or currently under assessment by the European Commission's Joint Research Centre, and a list of the Monitoring Reports submitted by signatories, are available. To evaluate the progress made towards their objectives, a Covenant of Mayors signatory is requested to submit an MR every two years after the adoption of its Action Plan related to the intended mitigation and adaptation actions, and at least every four years, the emission inventory of the action plan is updated, so as to verify the progress related to resilience to climate change, the reduction of emissions and energy consumption.

Information on the Italian signatories regarding the availability of the MRs was spatialized into a GIS environment. Such data deriving from the CoM website were collected in a comma-separated values (CSV table and merged with the resident population data as of 1 January 2020 from ISTAT [23] in order to be able to perform basic statistics identifying per capita impacts.

The data were collected for all Italian regions, determining how many Municipalities per region had submitted a SEAP or not.

From the CoM website, selecting Italy as the country, signatories according to the CoM classification were selected and were spatialized in the GIS environment. This approach of locating every signatory and not only reporting the picture from the CoM website differentiates this work from others [11,13]. The signatories were divided according to commitment into three classes (see Table 1):

- First, 2020: towns, cities and regions voluntarily committed to reducing their $\mathrm{CO}_{2}$ emissions beyond 20\%, below 1990 levels, by 2020, describing mitigation actions in a SEAP template. The SEAP includes energy-related actions tackling the largest emitting activity sectors in the city to achieve an increase in energy efficiency and the use of renewable energy sources (RES). They represent the highest number (2747) in term of signatories per commitment, with $85 \%$ of the total signatories.

- Second, 2030 \& ADAPTATION: the initial greenhouse gas emission reduction commitment and integrating adaptation to climate change were strengthened by three pillars: mitigation (an at least $40 \%$ emission reduction target by 2030); adaptation to climate change; and secure, sustainable and affordable energy. The label ADAPTATION is related to the Mayors Adapt initiative, which supports local authorities to develop and implement local adaptation strategies. This class, which contains the lowest number in terms of signatories (82) with only $3 \%$, represents the youngest signatories in terms of the numbers signed up per year (from 2016 to today).

- Third, 2020, 2030 \& ADAPTATION: this class includes the signatories that signed up to $\mathrm{CoM}$ and strengthened their commitments to decreasing $\mathrm{CO}_{2}$ emissions from $20 \%$ by 2020 to $40 \%$ by 2030 with the development and implementation of local adaptation strategies. This class, with 470 signatories ( $15 \%$ of the total signatories), is significant because it represents those signatories who intend to improve their commitments submitted. 
Table 1. Italian signatories per commitment.

\begin{tabular}{cc}
\hline & Country: Italy \\
\hline Commitment & Signatories \\
\hline 2020 & 2747 \\
$2030 \&$ ADAPTATION & 82 \\
2020,2030 \& ADAPTATION & 470 \\
TOTAL & 3217 \\
\hline
\end{tabular}

Figure 1 shows a flowchart of the research process, highlighting input data sources, the procedural approach and the analytical phases leading to the conclusions.

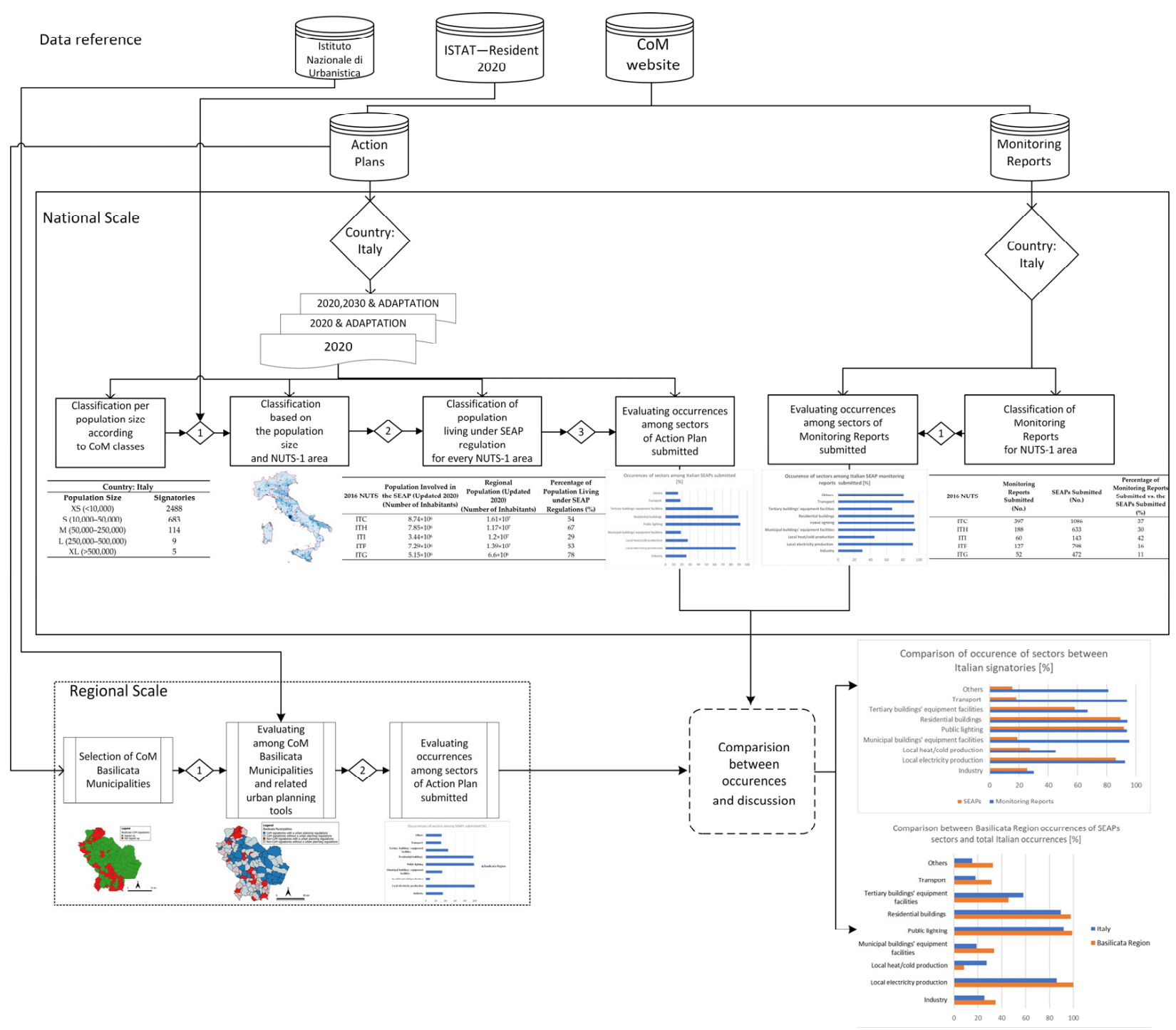

Figure 1. Methodology flowchart for the research process.

After this overall assessment in terms of signatories, all from the CoM website, it was possible to investigate how many signatories had developed a MR, collecting information on the sectors included and computing basic statistics such as the most recurrent sectors.

It is interesting, following the trend of the CoM signatories in terms of membership and comparing it with the key dates mentioned above, to know if there is an intention to increase the number of the CoM signatories supported by these initiatives or not. 
An evaluation of the territorial membership of the CoM compared to the resident population allows us to understand the impacts of European policies on the resident population, referring to the population size suggested by the CoM and the geographical distribution of the CoM Municipalities.

Starting from the official CoM DB, it is possible to estimate the occurrence of the main areas of intervention allowed in SEAPs for the entire national database. Some statistics were proposed to understand how the Municipalities have organized the interventions on the territory and select the most recurrent areas of action between the sectors in the SEAPs.

In order to compare the institutional planning provided by the law as opposed to European plans on climate or energy such as SEAPs, the data concerning institutional urban planning that were derived from the report of the Italian Urban Planning Institute (Istituto Nazionale di Urbanistica (INU)) [24] were merged with the information about the CoM signatories, considering, as a case study, the Basilicata Region.

\section{Results}

The results are divided into three sections, investigating the Italian CoM experience with related Monitoring Report (MR) and a final focus on the Basilicata Region, selected as the study case. The first section explores the Italian CoM experience (2008-2020), evaluating the number of Italian signatories and SEAPs submitted, the size of the signatories in terms of the resident population as of 2020, the resident population under SEAP regulation as of 2020, and the occurrences of the sectors in the Italian SEAPs. The second section is related to the MRs, considered a fundamental step in evaluating the SEAPs. Data on the MRs available on the CoM website, in terms of sector occurrences, are reported and compared to the Italian SEAPs submitted. The third section focuses on the Italian experience through the case study of the Basilicata Region, where CoM signatories are $64 \%$ of the total Basilicata Municipalities.

\subsection{The Italian CoM Experience (2008-2020)}

In order to analyze the status of the CoM experience in Italy (on a national scale), we compared the trends of the CoM signatories to the SEAPs submitted for the period 2008-2020, labelling in Figure 2 the relevant Policy Making Milestones (PMMs):

- The 2008 Launch of the Covenant of Mayors (CoM): a mainstream European voluntary movement involving local authorities in the development and implementation of sustainable energy and climate policies. Since its launch in 2008, the initiative has progressively grown into a worldwide city movement, extending first to Europe's eastern and southern neighboring countries and then to Sub-Saharan Africa.

- The 2013 Launch of Mayors Adapt: based on the same principles as the CoM, this initiative focused on adaptation to climate change, inviting local governments to demonstrate leadership in adaptation, and supporting them in the development and implementation of local adaptation strategies.

- $\quad$ The 2015 Launch of the Covenant of Mayors for Climate \& Energy: signatory cities actively support the implementation of the EU 40\% GHG-reduction target by 2030 and agree to adopt an integrated approach to climate change mitigation and adaptation, and to ensure access to secure, sustainable and affordable energy for all. In the same year, 196 state parties adopted The Paris Agreement [2], an agreement within the United Nations Framework Convention on Climate Change (UNFCCC) with the aim of strengthening the global response to the threat of climate change by keeping the global temperature rise this century well below 2 degrees Celsius above preindustrial levels and pursuing efforts to limit the temperature increase even further, to 1.5 degrees Celsius.

- The 2016 Launch of the Global Covenant of Mayors for Climate and Energy (GCoM), which merges the Covenant of Mayors for Climate and Energy and Compact of Mayors, into an international alliance of local governments with a shared long-term vision of supporting voluntary action to combat climate change and move to a low-emission 
and resilient society. In the same year, in May 2016, the Pact of Amsterdam was launched: The Urban Agenda for the EU [25]. It represents a new multi-level working method promoting cooperation between Member States, cities, the European Commission and other stakeholders in order to stimulate growth, livability and innovation in the European cities and to identify and successfully tackle social challenges.

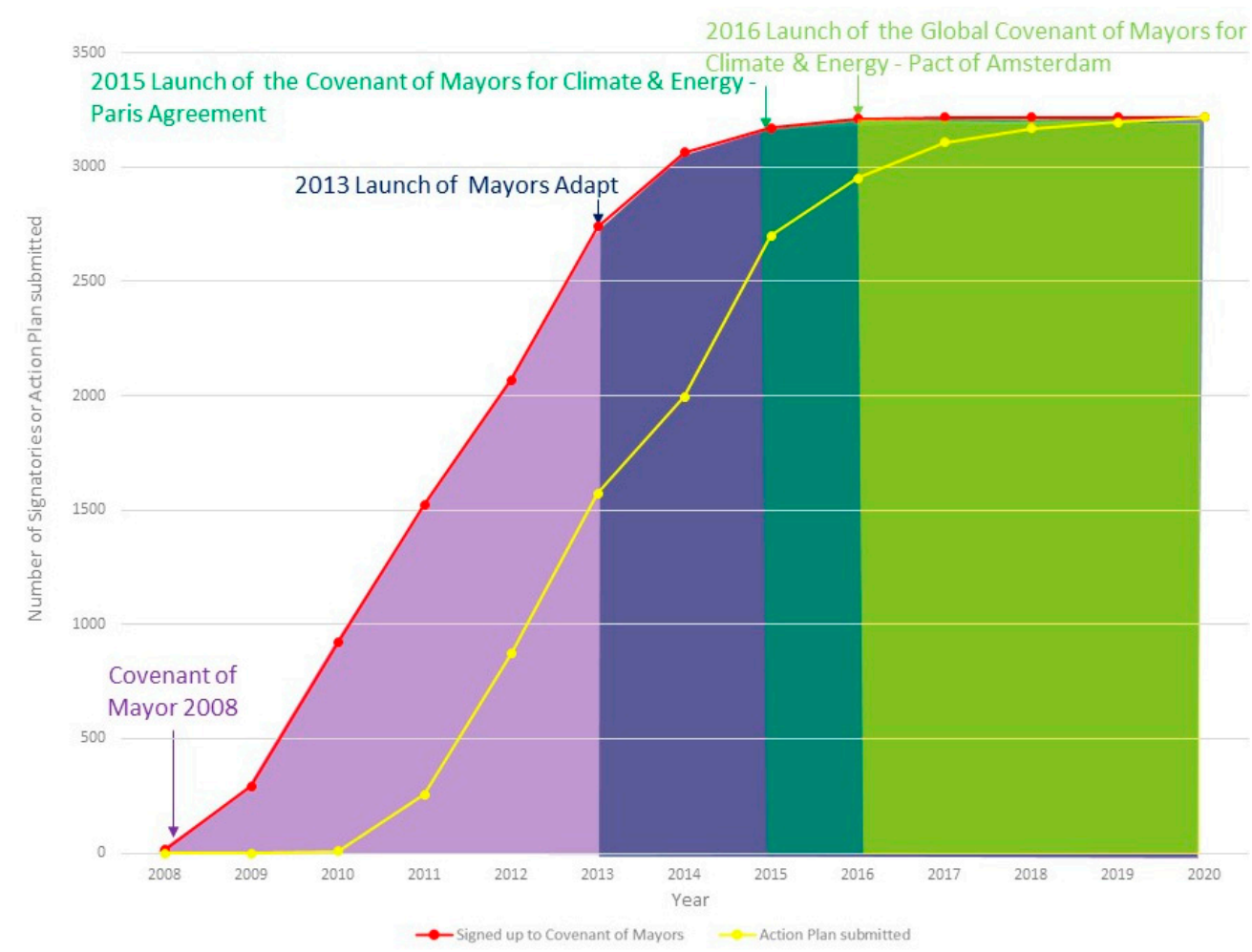

Figure 2. CoM signatories compared to Action Plans submitted for the period 2008-2020.

From a temporal point of view, it is possible to affirm that those PMMs did not affect the evolution of CoM implementation. As a matter of fact, it is possible to recognize a logistic curve starting from the CoM Launch in 2008 that reaches a plateau around 2016 in terms of the signatories and in 2019 in terms of the Submitted Action Plans. If the GCoM has the objective of increasing the number of Municipalities taking part, some specific actions are needed in order to increase the trend to overcome the logistic plateau.

According to the CoM general indicators, the signatories were classified, per resident population, into five classes from XS to XL (see Table 2). This classification does not take into account the fact that the population size of the signatories in Italy could refer either to a single municipality or to a group of Municipalities. The latter is the case for unions/associations of small Municipalities with populations under 5000 inhabitants, called "piccoli comuni" by the National Association of Italian Municipalities. This represents a discrepancy between the number of signatories on the CoM website and the actual number of Municipalities that are committed to the SEAP implementation: we have a number of Municipalities committed in the CoM implementation larger than the number of the submitted SEAPs. In the Italian case, we have 3299 CoM signatories (see Figure 3), which include 104 unions/associations of Municipalities. The Municipalities included in those 104 unions/associations comprise 706 small Municipalities (representing 21\% of the total CoM signatories); therefore, the total number of Italian Municipalities implementing a SEAP regulation is 3901 (about $49 \%$ of the Italian Municipalities). 
Table 2. Italian signatories per population class (source: CoM database (DB)).

\begin{tabular}{cc}
\hline & Country: Italy \\
\hline Population Size & Signatories \\
\hline XS $(<10,000)$ & 2488 \\
S $(10,000-50,000)$ & 683 \\
M $(50,000-250,000)$ & 114 \\
L $(250,000-500,000)$ & 9 \\
XL $(>500,000)$ & 5 \\
\hline
\end{tabular}

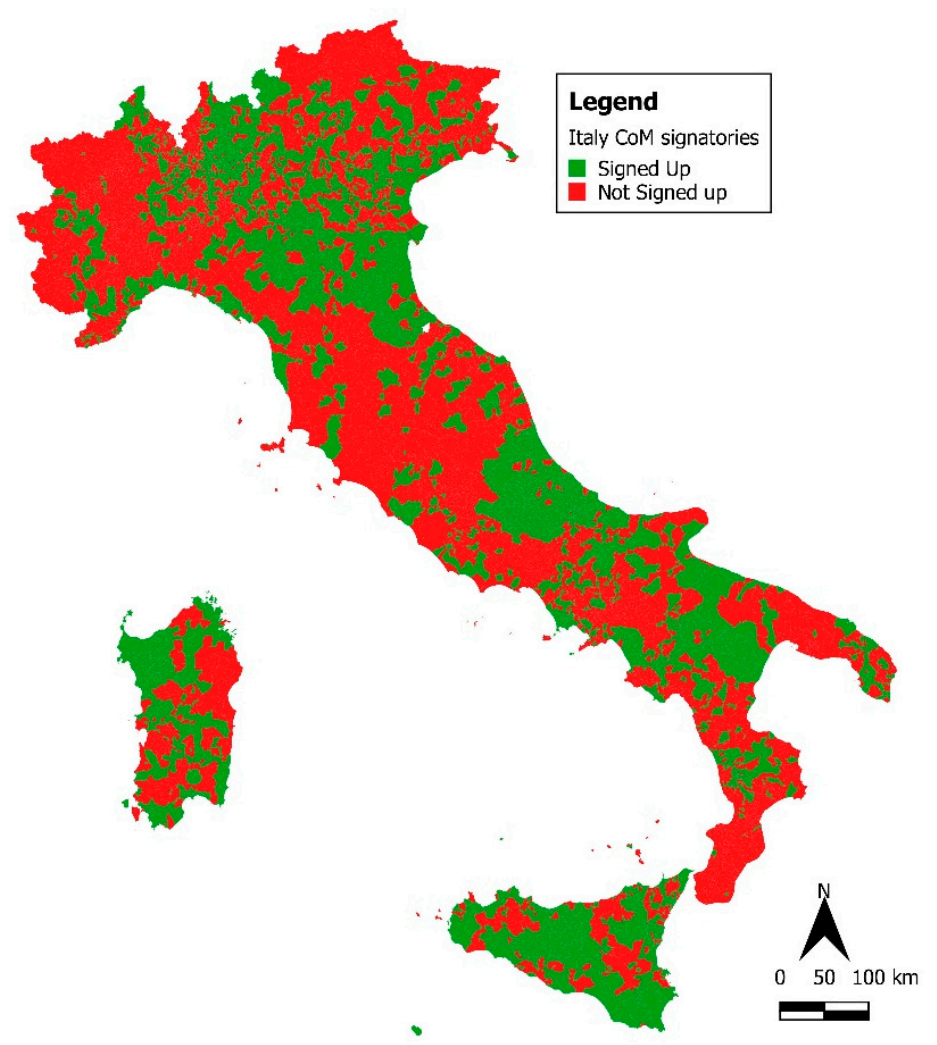

Figure 3. Italian CoM signatories, 2020.

In Table 3, the percentage of the CoM Municipalities per NUTS 1 are reported. The NUTS 1 classification subdivides Italy into five areas:

1. ITC-NORTH-WEST;

2. ITH-NORTH-EAST;

3. ITI-CENTRE (IT);

4. ITF-SOUTH;

5. ITG-ISLANDS.

It is important to point out that the ITG sub-area, with the highest percentage, includes Sicily and Sardinia, whereas the central part of the country has the lowest contribution in terms of signatories. 
Table 3. Sustainable Energy Action Plants (SEAPs) submitted or not, and related total percentages for Italy NUTS 1.

\begin{tabular}{ccccc}
\hline \multicolumn{5}{c}{ Country: Italy } \\
2016 NUTS & $\begin{array}{c}\text { Signatories with SEAP Submitted } \\
\text { (No.) }\end{array}$ & $\begin{array}{c}\text { No-CoM Municipalities } \\
\text { (No.) }\end{array}$ & $\begin{array}{c}\text { Total Municipalities } \\
\text { per NUTS (No.) }\end{array}$ & $\begin{array}{c}\text { Percentage of SEAP } \\
\text { Submitted of Total (\%) }\end{array}$ \\
\hline ITC & 1086 & 1909 & 2995 & 36 \\
ITH & 633 & 755 & 1388 & 46 \\
ITI & 143 & 828 & 971 & 15 \\
ITF & 798 & 985 & 1783 & 45 \\
ITG & 472 & 295 & 767 & 62 \\
\hline
\end{tabular}

Furthermore, it is interesting to consider the updated resident population data (2020) in order to assess the share of inhabitants living in a SEAP Municipality and, therefore, the beneficiaries of the actions included in the action plans (see Figure 4). It is possible to affirm that for the ITF and ITG areas, generally identified as the South of Italy, the coverage of the population by SEAPs is characterized by a high percentage (ITF: $53 \%$; ITG: $78 \%$ ) of the total regional population. In Northern Italy, the high population percentage involved in the SEAPs is reached owing to the contribution of those Municipalities with M or L population sizes (for the population sizes, see the previous Table 2), mostly concentrated in Eastern Italy. The following table (see Table 4) represents the spatial distributions of those variables.

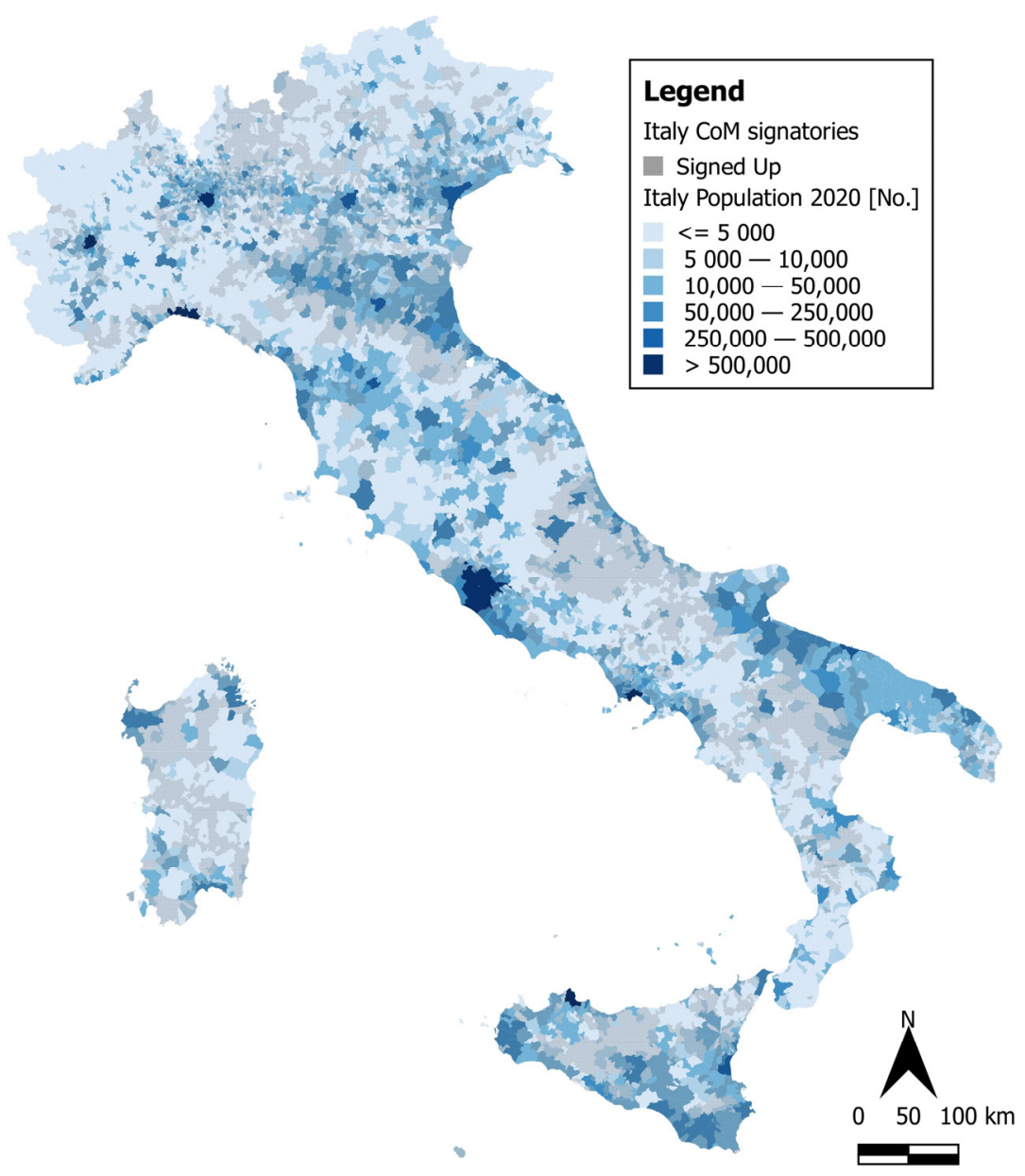

Figure 4. Resident Italian population (2020) living in CoM Municipalities. 
Table 4. Population involved in the SEAP for Italian NUTS 1.

\begin{tabular}{cccc}
\hline 2016 NUTS & $\begin{array}{c}\text { Population Involved in the SEAP } \\
\text { (Updated 2020) } \\
\text { (Number of Inhabitants) }\end{array}$ & $\begin{array}{c}\text { Regional } \\
\text { Population (Updated 2020) } \\
\text { (Number of Inhabitants) }\end{array}$ & $\begin{array}{c}\text { Percentage of Population Living } \\
\text { under SEAP Regulations (\%) }\end{array}$ \\
\hline ITC & $8.74 \times 10^{6}$ & $1.61 \times 10^{7}$ & 54 \\
ITH & $7.85 \times 10^{6}$ & $1.17 \times 10^{7}$ & 67 \\
ITI & $3.44 \times 10^{6}$ & $1.2 \times 10^{7}$ & 29 \\
ITF & $7.29 \times 10^{6}$ & $1.39 \times 10^{7}$ & 53 \\
ITG & $5.15 \times 10^{6}$ & $6.6 \times 10^{6}$ & 78 \\
\hline
\end{tabular}

The structure of the SEAPs is based on three main features:

1. The overall strategy;

2. The Baseline Emission Inventory (BEI);

3. The Sustainable Energy Action Plan.

In the second and third features are the "sectors" included in the SEAP structure: industry, local electricity production, local heat/cold production, municipal buildings, equipment/facilities, public lighting, residential buildings, tertiary buildings, equipment/facilities, transport, and others. Therefore a "sector" represents an intervention area characterized by specific actors, emissions, and actions. For these sectors, every CoM signatory defines actions and investments. We investigated the occurrence of these sectors among the Italian SEAPs submitted, in order to identify the occurrences and, consequently, obtain a comprehensive national picture of the sectoral specialization of the SEAPs (see Figure 5).

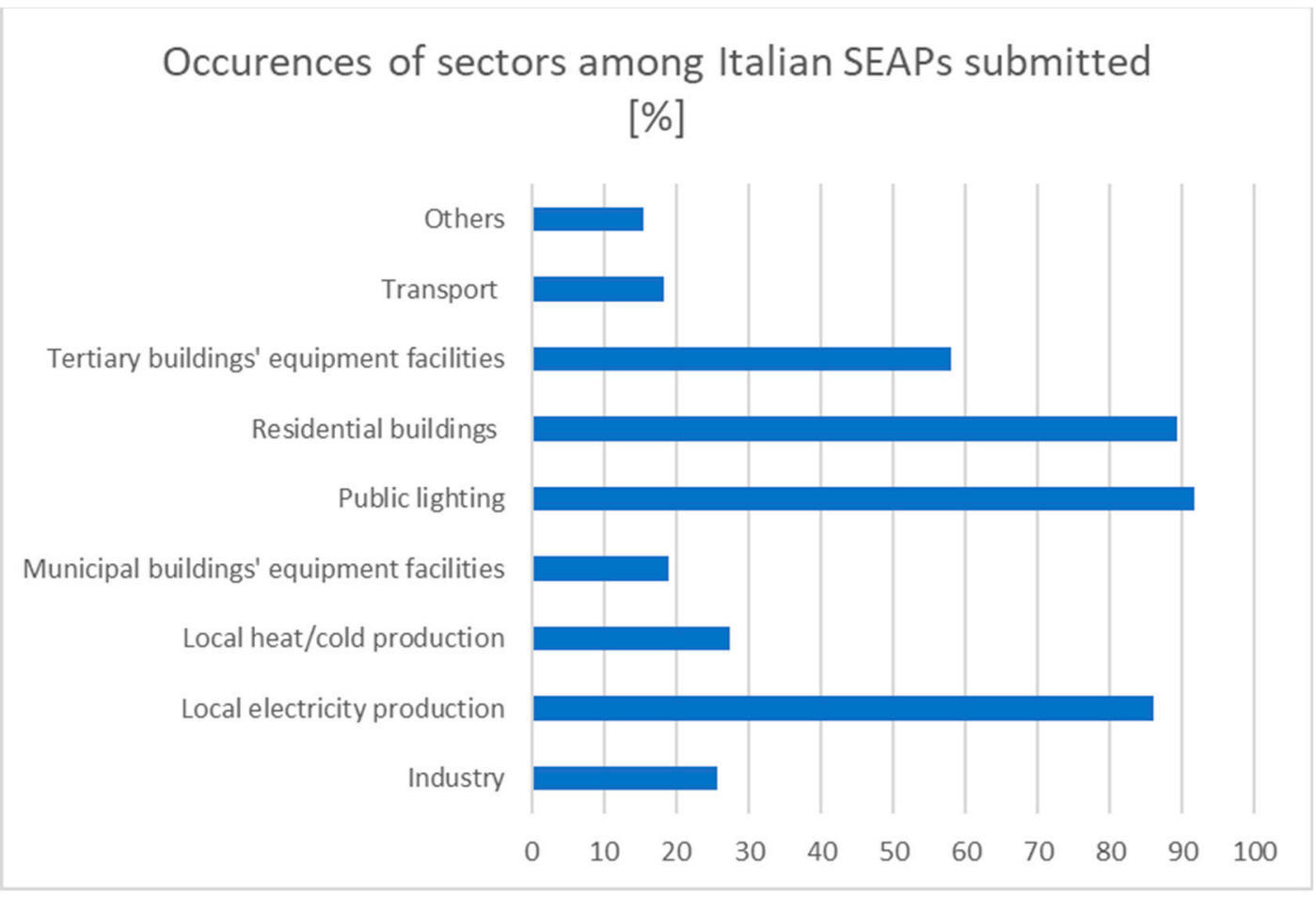

Figure 5. Occurrences of sectors among the Italian SEAPs submitted.

\subsection{Monitoring Reports: A Foundamental Step for Evaluating the SEAP}

Monitoring Report (MR) represent an important step in determining what the quantitative progress for the planned actions is, and a point for the evaluation of the performance reached. They are a part of the CoM commitments, which allow measuring progress towards the targets set in the action plan. Reports can be of two types: a qualitative MR, 
at least every second year after the submission of the action plan, and a full quantitative implementation report, at least every fourth year after the submission of the action plan, for evaluation purposes. Covenant signatories have to compile a Monitoring Emission Inventory (MEI) every 4 years in order to compare the Baseline Emission Inventory (BEI) created with the SEAP and the progress in terms of $\mathrm{CO}_{2}$ emission reduction. Monitoring energy consumption and $\mathrm{CO}_{2}$ emissions allows an understanding of whether the signatories are on track towards reaching the target or, if not, identifying factors that affect the results. In brief, MRs allow evaluating:

- Any changes to the overall strategy as well as updated figures on the attribution of staff and financial capacities;

- The amount of final energy consumption and associated $\mathrm{CO}_{2}$ emissions by energy carrier and by sector in the year under observation-the main objective is to monitor the evolution of $\mathrm{CO}_{2}$ emissions over time;

- The implementation status of the key actions.

In the section "Progress" of the CoM website, data on the signatories that had uploaded a MR are presented. In Tables 5 and 6, we report the data of the available MRs for Italy. Comparing the number of submitted SEAPs and the number of submitted MRs, it is possible to highlight that the percentage of monitored SEAPs does not exceed $32 \%$ : a very low share of the total number of Action Plans.

Table 5. Monitoring Reports available on the CoM website versus the SEAPs submitted.

\begin{tabular}{ccc}
\hline SEAPs Submitted (No.) & $\begin{array}{c}\text { Monitoring Reports Submitted by } \\
\text { Signatories (No.) }\end{array}$ & $\begin{array}{c}\text { Percentage of Monitoring Reports on } \\
\text { SEAPs Submitted (No.) }\end{array}$ \\
\hline 3217 & 1035 & 32 \\
\hline
\end{tabular}

Table 6. Monitoring Reports submitted compared to the SEAPs submitted for the NUTS regions.

\begin{tabular}{cccc}
\hline 2016 NUTS & $\begin{array}{c}\text { Monitoring Reports Submitted } \\
\text { (No.) }\end{array}$ & $\begin{array}{c}\text { SEAPs Submitted } \\
\text { (No.) }\end{array}$ & $\begin{array}{c}\text { Percentage of Monitoring Reports } \\
\text { Submitted vs. the SEAPs Submitted (\%) }\end{array}$ \\
\hline ITC & 397 & 1086 & 37 \\
ITH & 188 & 633 & 30 \\
ITI & 60 & 143 & 42 \\
ITF & 127 & 798 & 16 \\
ITG & 52 & 472 & 11 \\
\hline
\end{tabular}

We calculated the occurrences of the SEAP sectors (industry, local electricity production, local heat/cold production, municipal buildings, equipment/facilities, public lighting, residential buildings, tertiary buildings, equipment/facilities, transport, and others). The occurrence of the sectors as shown in Figure 6 indicates significant differences between the SEAPs and the MRs. This is pertinent information for understanding that in the implementation phase, many changes occurred in the overall strategy. This may reflect the flexibility of the SEAP as an urban development program in adapting the implementation based on local issues that emerge in a specific implementation sector; on the other hand, it could also be an indicator of a lack of robustness of the ex-ante evaluation and planning phases, based mainly on the BEI assessment and targets but not considering the relationship of such a framework with the contextual feasibility of the envisaged actions. The SEAPs, during the implementation phase, undergo an adaptation procedure that effectively connects the implementations with specific requirements for the places: this brought about a change in the sector shares of the investments. Additionally, changes in the implementation phase come about mainly in those sectors that are characterized by public management: the "transport" sector occurrence presents an increase between the planning and implementation phases of about $+70 \%$; for "Municipal buildings, equipment and facilities", it is $+70 \%$. Different indications come from those sectors of which private actions/investments are characteristic: 
"Local electricity production" increased between the planning and implementation phases by about $+8 \%$; "industry", by $+5 \%$.

\section{Comparison of occurence of sectors between Italian signatories [\%]}

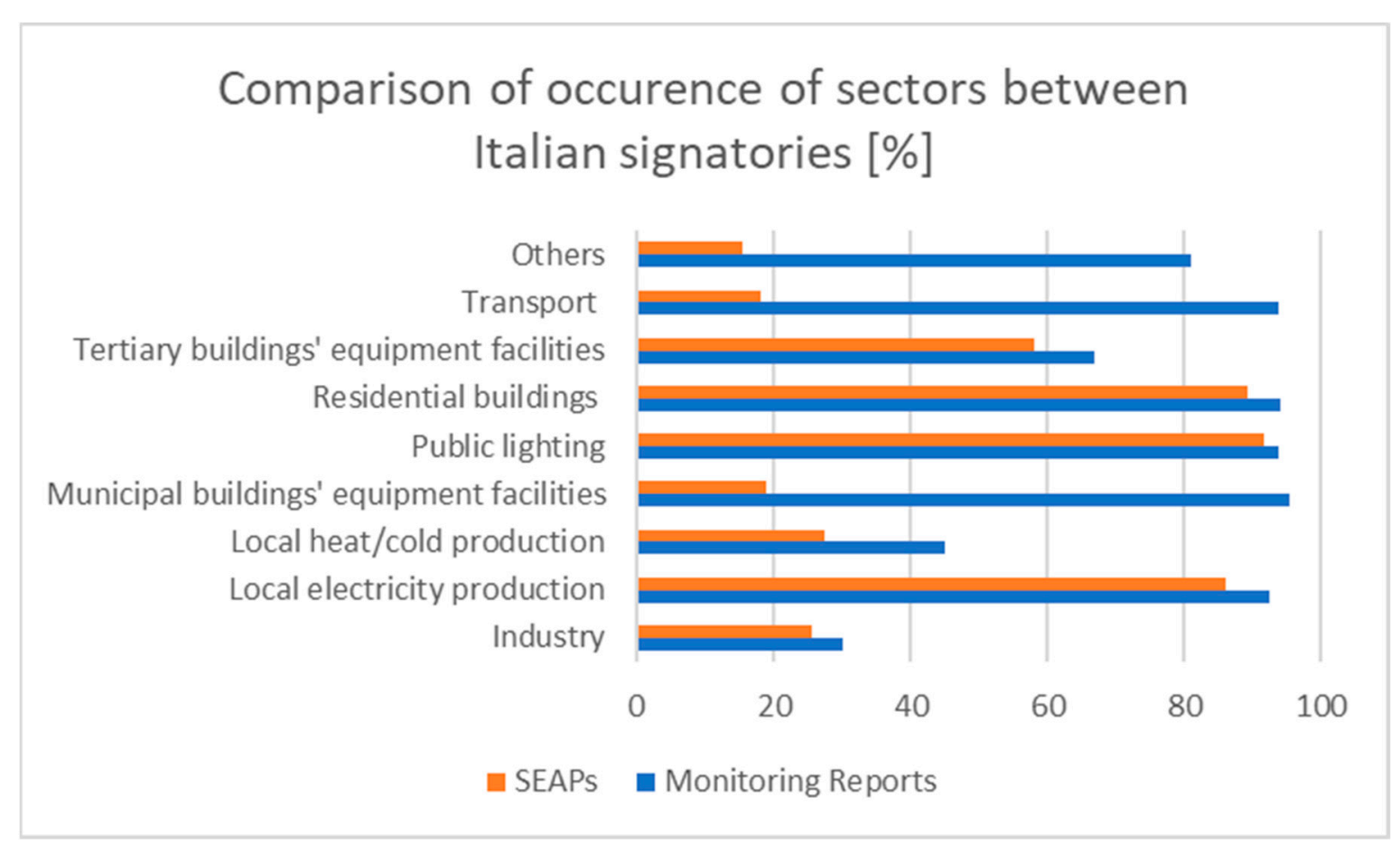

Figure 6. Comparison of the occurrence of the sectors between Italian Monitoring Reports and SEAPs.

The figures reported below also allow observing that from the planning phase to the monitoring phase, the occurrence of the intervention sectors increased in total. This means that Municipalities undergo a process of extending the scope of each plan by probably including ongoing local actions and investment trends in energy saving. This is not fully coherent with a rational planning approach [26] but mainly so with a strong governance oriented towards achieving declared targets.

\subsection{Focusing on the Italian SEAP Experience: The Case Study of the Basilicata Region}

If we consider the share of signatories out of the total number of Municipalities, the experience of the CoM in the Basilicata Region provides satisfying results: of 133 Municipalities, 83 have presented a SEAP (corresponding to $64 \%$ of the total Basilicata Municipalities), and this large involvement was achieved owing to a fruitful institutional collaboration that links the Municipalities to a public services company: the Lucana Energy Company (SEL), under the supervision of the Potenza Province (Covenant Coordinator). SEL is called upon to "support regional energy policies", implementing "actions aimed at improving the management of energy supply and demand, promoting energy saving and efficiency and promoting a better use of local, conventional and renewable energy resources, also operating in the electricity and gas markets". SEL, among its projects, promotes the initiative of $\mathrm{CoM}$ and has supported Municipalities from a technical perspective for the entire process of the CoM sign-up, and the technical development of the SEAPs according to a regional Baseline Emission Inventory (BEI) (2009). In Table 7, the numbers and relative percentages of the Basilicata CoM signatories, distinguished by the two Provinces, are reported: Potenza and Matera. The data that emerge show that the signatory Municipalities of the Province of Matera are only $24 \%$ of the Basilicata Municipalities covered by the CoM. The data are also spatialized in Figure 7 in terms of CoM signatories or non-CoM signatories. 
Table 7. Basilicata CoM signatories.

\begin{tabular}{cccc}
\hline Basilicata Province & $\begin{array}{c}\text { CoM Signatories } \\
\text { (No.) }\end{array}$ & $\begin{array}{c}\text { Total Municipalities per } \\
\text { Province } \\
\text { (No.) }\end{array}$ & $\begin{array}{c}\text { Percentage of Signatories of Total Basilicata } \\
\text { Municipalities (\%) }\end{array}$ \\
\hline Potenza & 52 & 100 & 40 \\
Matera & 31 & 31 & 24 \\
\hline
\end{tabular}

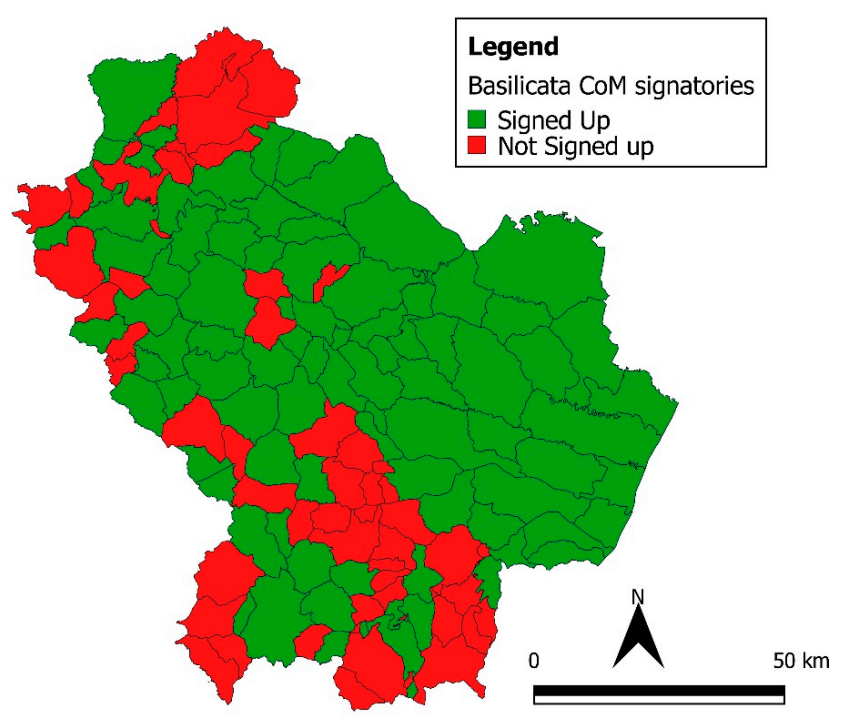

Figure 7. Basilicata CoM signatories.

Today, it is relevant to highlight the collaboration between UNIBAS-SI and SEL in promoting research [27] and providing technical-scientific support for Public Authorities under the specific "Low Carbon Economy transition partnership" cooperation agreement (refs. [28-30]).

Concerning the urban planning framework in the Basilicata Region, in 1999, the Basilicata Regional Urban Planning Law was approved [31]. It is a structured framework of rules and tools for multi-level territorial planning: plans at different scales (Regional, Provincial and Municipal) and processes for managing the development of urban planning (in Figure 8, a summary flowchart is proposed). Every Municipality has to develop its own Urban Plan and manage the evolution of the urban settlements, the implementation of infrastructures (such as streets, highways and railways), the implementation of environmental protection measures, and land use according to resident population trends and strategic development perspectives. In 2020, only 57 of 131 Municipalities adopted an Urban Plan in line with the Regional Urban Planning Law (44\% of the total Basilicata Municipalities) [24]. This is not representative of a high implementation level of the Regional Planning Law, especially in consideration of the fact that since 1999 (the date of the approval of the Regional Law), the Municipalities have had ample time to implement the complex process of urban planning according to the specific requirements defined by the legislator. Moreover, it represents a compulsory task for local Municipalities, and those who do not approve the Municipal Plan should be placed under receivership. We also have to say that such an option has never been adopted, and this is another indicator of the fragility of the urban planning system at a regional level.

Among the Municipalities that adopted the Urban Plan (57 out of 131), 41 are also CoM signatories; this means $31 \%$ of the total Basilicata Municipalities. It is interesting to highlight that the CoM signatories without urban planning regulations are 42 (almost the same in number as in the previous group). Additionally, the Municipalities that are not CoM signatories and that have not approved an Urban Plan under the current regional planning law represent $25 \%$ (32 Municipalities out of 131). 
In Table 8 and Figure 9, the numbers and related percentages of those categories are represented.

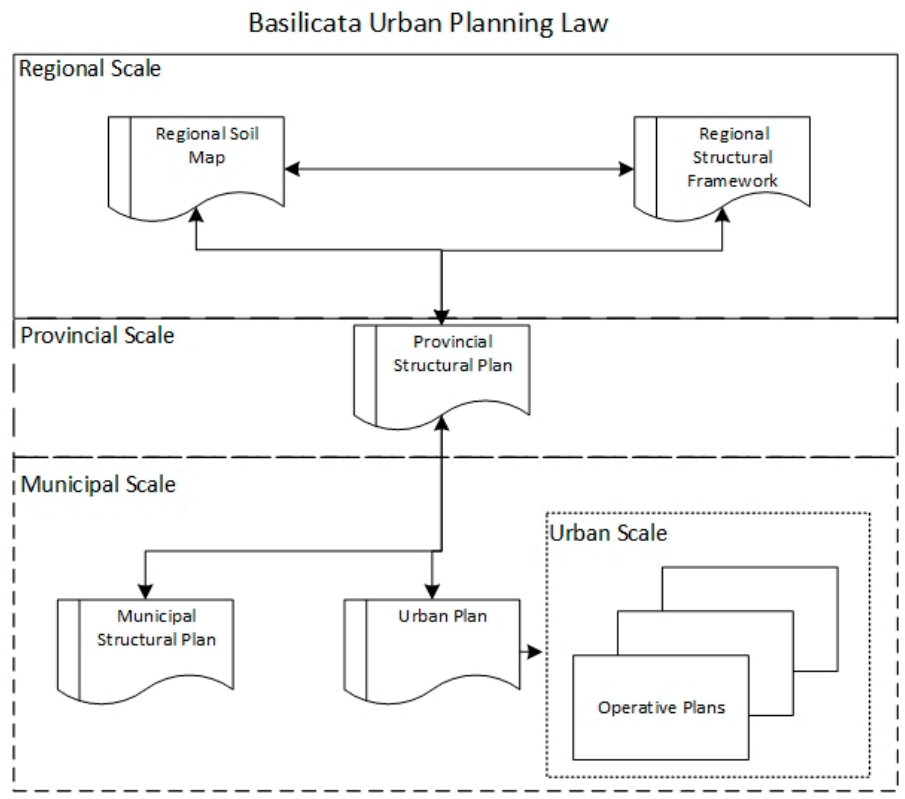

Figure 8. Flowchart of the Basilicata Urban Planning Law.

Table 8. Basilicata Municipalities in relation to urban planning tools.

\begin{tabular}{ccc}
\hline Basilicata Municipalities & Number of Municipalities & $\begin{array}{c}\text { Percentage Total Basilicata } \\
\text { Municipalities (\%) }\end{array}$ \\
\hline CoM signatories with urban planning regulations & 41 & 31 \\
CoM signatories without urban planning regulations & 42 & 32 \\
Non-CoM signatories with urban planning regulations & 16 & 12 \\
Non-CoM signatories without urban planning regulations & 32 & 25 \\
\hline
\end{tabular}

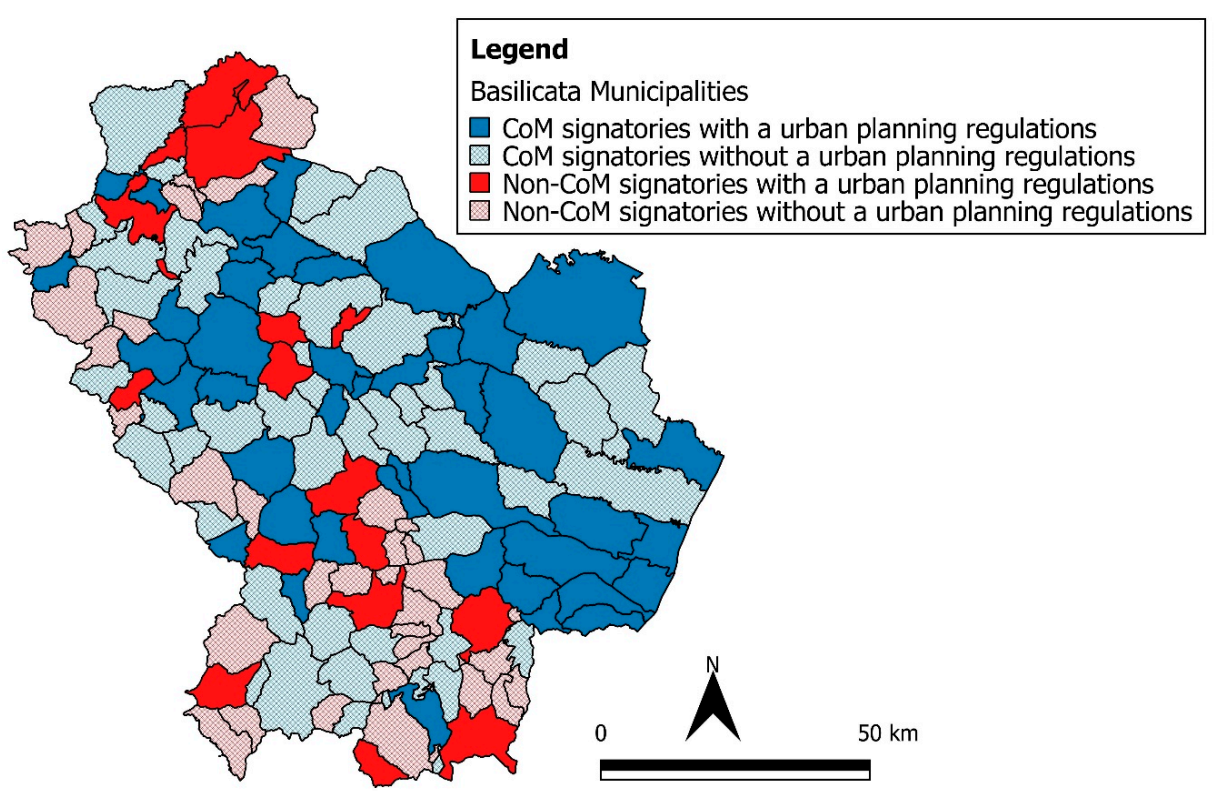

Figure 9. Municipalities signed up to the CoM with/without urban planning regulations. 
It is possible to affirm that a relevant share of Local Administrations addressed the SEAP operative issues that are related to the organization of urban development projects and the interventions in the sector of energy efficiency. In those Municipalities, the SEAP becomes an alternative to the more complex process of urban planning according to the current Regional Planning Law. The perception is that the SEAP substitutes the urban plan according to its capacity to impact and promote extensive urban transformations connected to the mainstream EU policies and funding.

From the disciplinary perspective, it is necessary to underline that such processes are realized without a systemic assessment of the urban structure and strategic vision including all the components of the "Urban Plan" that better allow assessing the impacts (positive or negative) of such implementation. Moreover, the place-based [32] or context-based [33] approach promoted by the EU in the New Cohesion Policy framework [34,35] becomes weak in its connection with a comprehensive territorial assessment that we refer to as the new planning rationality $[6,26,36]$

In investigating the sectors of the SEAPs of the Basilicata Municipalities, and comparing their occurrences with the corresponding occurrences at a national scale (see Figure 10), some differences arise:

- Sectors such as "local electricity production", "residential buildings" and "public lighting" have occurrences close to $100 \%$, while sectors such as "transport", "industry" and "others" have occurrences 50\% greater than the Italian trend; this underlines a strong interest in planning investments and searching for funding, supported by European policies, from public and private stakeholders.

- The "transport" sector has an occurrence close to 50\% more than the Italian trend, but the interventions provided do not take into account the development or implementation of sustainable transport policies but, instead, the replacement of the old vehicle fleet with low-emission vehicles or economic support for buying electric vehicles.

- Sectors such as "local heat/cold production" or "tertiary buildings' equipment/ facilities" have occurrences that are lower than the Italian trend; this highlights that investments in these sectors are realized not by choosing the SEAPs but via other institutional ways (i.e., the Ministry of Economy, European Regional Development Fund or other European Funds).

- Considering the overall sectors and the typologies of the interventions provided for the Basilicata Municipalities, it is noted that there is strong support for the European policies by the Municipalities, probably due to the certainty of the implementation of the interventions and a more flexible process with a high level of accountability compared to the institutional processes of urban planning.

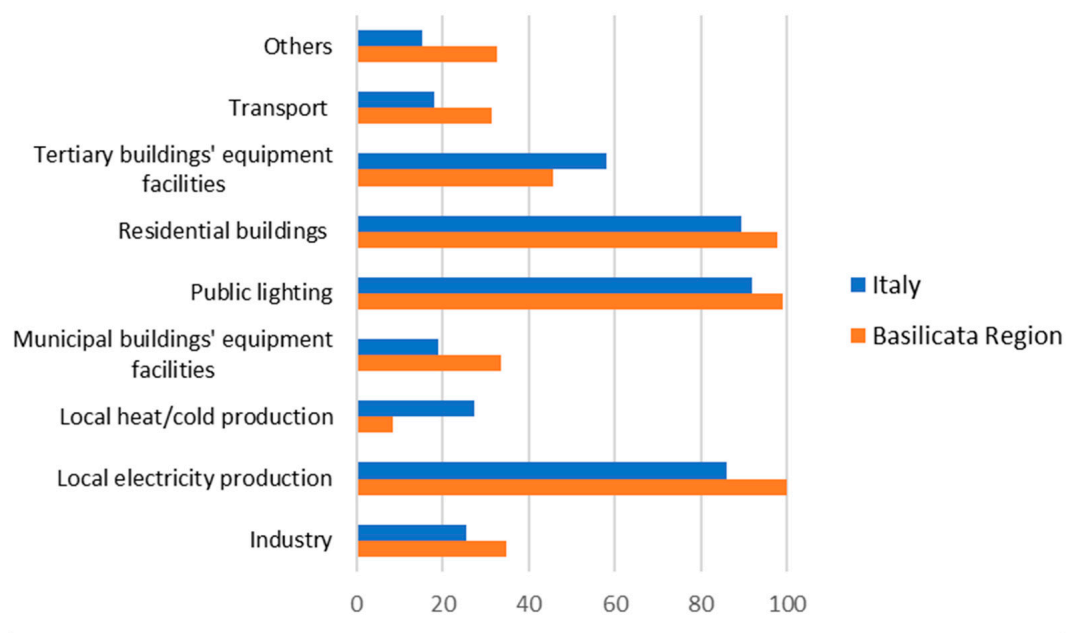

Figure 10. Comparison between occurrences of SEAPs submitted at national and regional scales. 
Despite the fact that $64 \%$ of the Basilicata Municipalities have submitted a SEAP, only one Municipality of 83 has correctly made available their MRs on the CoM website. This is a very critical point because in the circular process of the CoM, every signatory has to publish its MR after 2 years from the submission of its SEAP. In the Basilicata case, through investigations on the websites of the Municipalities and a direct survey of the technical structures responsible for the SEAP process, we discovered that two Municipalities delivered their MRs but did not complete the CoM procedures. The reasons for these very low numbers in terms of MRs compared to CoM signatories are that:

- Technical support in the second phase of the CoM process was not provided to the Municipalities after the initial stage when the Province of Potenza (Covenant Coordinator), in using regional funds, delivered a subsidiary technical function via the SEL company. The capacity of the Municipalities to manage the follow-up of the SEAP submissions was very low, and this delayed the evaluation of the SEAP implementation.

- The non-publishing of the MRs is also representative of the general condition of the non-implementation of the actions included in the SEAPs due to the lack of specific funding, the technical capacity to promote public tenders and procurements, and low interactions with private investors and local stakeholders.

In Figure 11, a spatialization of the data on the Basilicata Municipalities' SEAP sectors' occurrences is proposed so as to provide a territorial assessment of the CoM experience in the Basilicata Region.
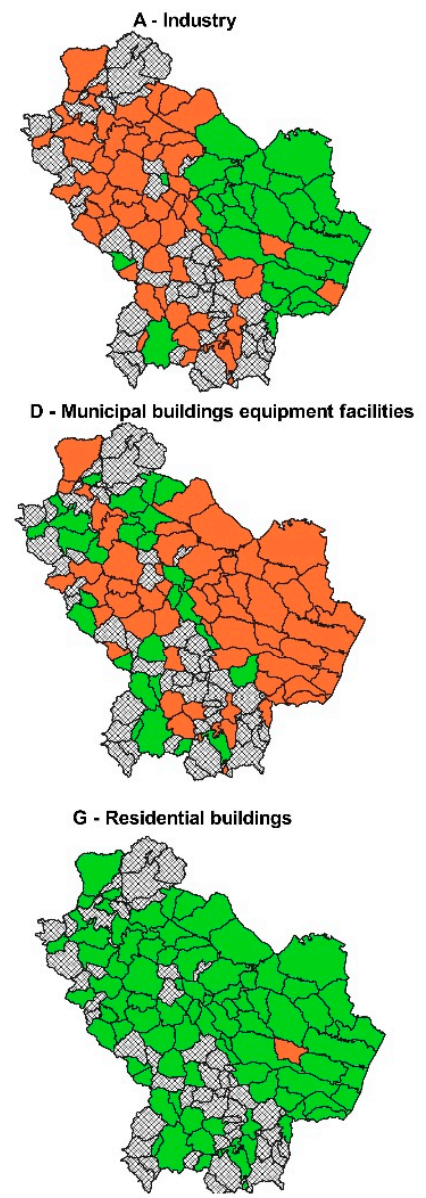

Basilicata Municipalities

Non-CoM Signatories
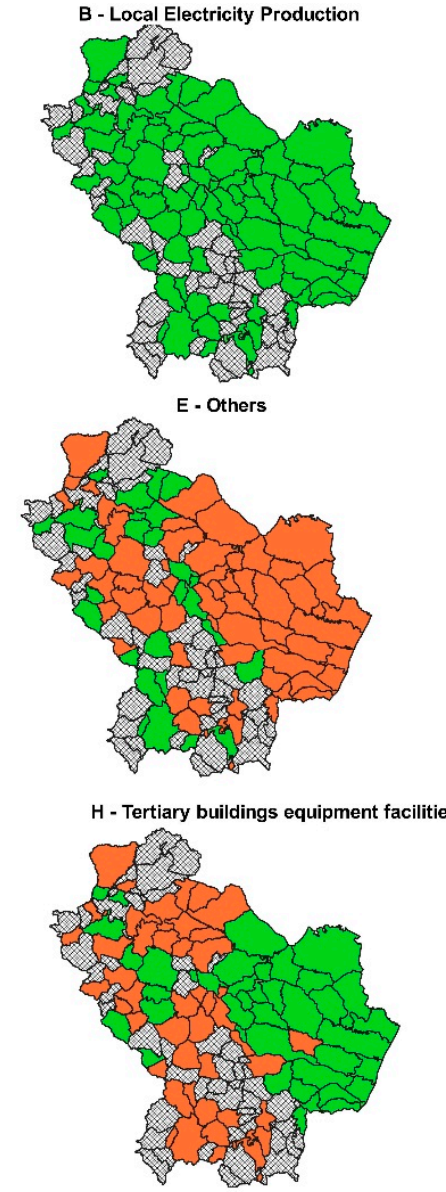

CoM Signatories with related SEAP sector
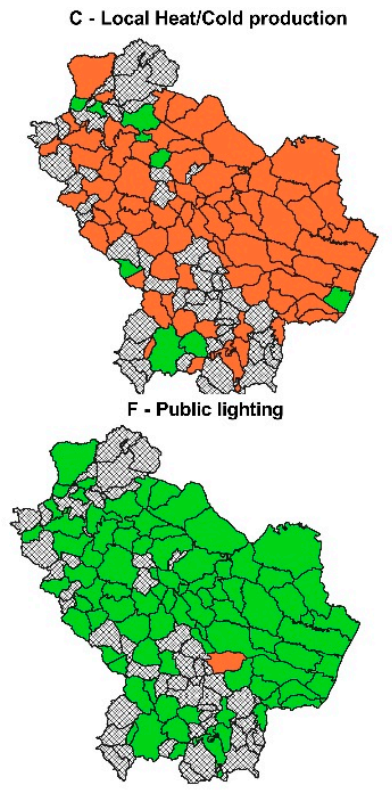

I- Transport

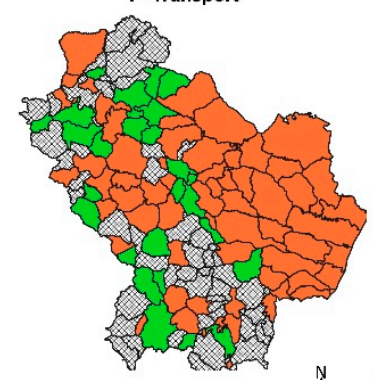

N $\begin{aligned} & 0510 \mathrm{~km} \\ & \square\end{aligned}$

CoM Signatories without related SEAP sector

Figure 11. Basilicata CoM Municipalities with related SEAP sectors. 
Considering only the SEAP sectors in the Basilicata Region (see Figure 11), their geographical distribution among the CoM Municipalities in the two Provinces of Potenza and Matera highlights some interesting results:

- Among all the Basilicata Municipalities, the sectors widely involved in the SEAPs are "residential buildings" (98\%), "public lighting" (99\%) and "local electricity production" $(100 \%)$, highlighting a place-based approach to the investments suggested, combining public and private interests/actors that join in the pursuit of the common goal of $\mathrm{CO}_{2}$ reduction.

- The Municipalities of the Matera Province have exhibited appreciable occurrences for the "industry" (93\%) and "tertiary (not municipal) buildings' equipment/facilities" (76\%) sectors among the Basilicata SEAPs submitted. This explains, on the one hand, the aim of improving the energy efficiency in the manufacturing processes and, on the other, the unbalanced planning of the interventions in these sectors for the Municipalities of the Potenza Province.

- Despite two Municipalities with over 5000 inhabitants, the "Municipal buildings" equipment/facilities" sector is included by the small Municipalities with resident populations under 5000 inhabitants. These Municipalities are almost all (96\%) from the Potenza Province and, from a geographical point view, are located in the inland areas of the Basilicata Region.

\section{Discussion}

Working on data available on the CoM website easily allows experts and common citizens to assess how the European Communities (represented through the Municipalities) have warned of topics about investments in renewable energies and also climate change mitigation and adaptation policies. The data are available in read-only format, and no open data or data distribution services are available. This may represent a barrier to encouraging data sharing and re-usage in sectoral studies and statistics.

Concerning the Italian data, the number of Italian signatories in the CoM that developed a SEAP corresponds to $41 \%$ of the total Italian Municipalities, a low number considering the relevance of the sector in the national strategic development policies. The themes of sustainable energy production and consumption and consequent investments in clean energy are hot topics not only in European policies and strategies but also in the UN programs $[8,37]$.

The percentage of Italian signatories who submitted a MR was only $32 \%$ of the total SEAP signatories. This is a proxy for understanding the commitment levels of the Municipality signatories.

It is interesting to look at the resident population of the SEAP signatories: most of them (2488) are small Municipalities (or unions of small Municipalities) with populations under 10,000 inhabitants. It is relevant to underline that, among the Municipalities with populations over 500,000 inhabitants, Rome is not in the official list of CoM Signatories. However, it adopted the SEAP in 2013 [38]. The large participation of small Municipalities in terms of inhabitants is bound to the choice of SEAPs as instruments used to plan and provide funding for ordinary interventions in the urban areas instead of institutional instruments (i.e., urban planning regulations, operational plans and programs established by National policies).

The figures of the CoM experience in Italy, as indicated in the official CoM DB, are not fully coherent with the effective status of the implementation process: as a matter of fact, a lot of missing data were identified, especially with regard to the MRs. That is why it is very difficult to achieve a comprehensive framework. This critical point results from the Basilicata study case, an example that represents a virtuous region in terms of signatories, with $64 \%$ of the Municipalities that signed up for the CoM submitting a SEAP, but only $4 \%$ of the municipalities developed an MR without official feedback from the CoM website.

The reasons for these critical issues are probably related to the lack of support offered to the Municipalities, who are always encouraged by energy service companies (such as 
SEL for the Basilicata Region) from the moment of the CoM submission to the development of the Action Plan and then left alone without guidelines for continuing further with the MRs.

The SEAP process worked until a qualified technical structure provided the necessary assistance in defining the action plans. After this phase, in the absence of adequate funding, the Municipalities demonstrated a technical weakness in the management of the subsequent phases or, worse, a low level of commitment with respect to the aims of the whole process.

The SEAPs are voluntary plans that, in the last few years, have deeply influenced urban development, sometimes out of the normative and spatial framework defined through urban plans. The results of the local investigation conducted in the Basilicata Region allowed us to point out that SEAPs could be an alternative planning tool compensating for the lack of urban plans according to the National/regional urban laws. This is a critical discrepancy between the CoM objectives and the local implementation purposes, mainly oriented towards facilitating project implementation based on sectorial public or EU funding opportunities rather than governing a territorial process of transition towards a more sustainable energy scenario [39].

The SEAPs are based on a bottom-up approach involving a complex body of public and private actors. However, in comparing the occurrences of the SEAP sectors, it appears that the "public" sectors (i.e., public lighting or municipal buildings' equipment/facilities) are the main intervention areas. This may be representative of a prevailing top-down approach that precludes the opportunity to build local private-public-people relations [40,41]. In this way, most of the investments are supported by municipal authorities and less by private investors or stakeholders, showing a poor relationship between the actions provided in the SEAPs and the urban or territorial transformations that have ensued.

\section{Conclusions}

This paper aimed at evaluating the state of the Italian CoM implementation, assessing the results achieved in terms of the Municipalities involved (CoM signatories), the SEAPs developed and the MRs submitted. Based on the analysis of the MRs data, we discussed some critical appraisals concerning the performance level of the CoM, highlighting, as with the conclusions discussed by the report 316/2020 of ISPRA (The Italian Institute for Environmental Protection and Research, ISPRA-Istituto Superiore per la Protezione e la Ricerca Ambientale) [42], how technical support for small Municipalities and the effective commitment of local decision makers may affect the effectiveness of the entire process of CoM implementation at a local level. The figures referred to the Basilicata Region case study are a measure of the discrepancy between the information available from the CoM official data and the effective implementation status at a local level.

This study delivered an assessment of the SEAP experience in Italy, which, in 2020, met its first deadline, passing the baton to the "new" CoM experience based on the Sustainable Energy and Climate Action Plan (SECAP), including the ambitious goal of climate adaption coupled with sustainable energy management.

The data from the CoM official website investigated took into consideration the CoM signatories, the resident population under SEAP Municipalities, the MRs submitted and the occurrences of sectors among the Italian signatories. The main highlights are:

- A total of 3901 out of 7903 Italian Municipalities (corresponding to $49 \%$ of all the Municipalities) have signed up to the CoM, but only $15 \%$ of the Italian signatories (in terms of the signatories, these are 470 out of 3217) have reinforced their commitments to decreasing $\mathrm{CO}_{2}$ emissions from $20 \%$ by 2020 to $40 \%$ by 2030 with the development and implementation of local adaptation strategies.

- From a geographical point of view, the distribution of SEAPs is widespread in the North-East and South of Italy, including the islands of Sicily and Sardinia, where the percentage of SEAPs submitted by the Municipalities is $62 \%$.

- Considering the same NUTS regions and comparing the percentages of the population involved by the SEAP and municipalities, there are geographical regions such as the 
"Nord-Ovest" (North-West) where the percentage of the total SEAPs submitted is less than the population involved by the SEAPs. This is mainly due to the involvement of a few Municipalities with M or L population sizes (according to the CoM classification) rather than a large number of Municipalities.

- The theme of the MRs is the critical point of the CoM process. Only $32 \%$ of the MRs of the total SEAPs submitted are available on the CoM website; this does not mean that the Municipalities do not develop their MRs but means that there is a lack of support to the Municipalities uploading data on the CoM website. In this way, it is not possible to know how many MRs there are and how much progress has been achieved.

- In comparing the sectors involved by the Italian Municipalities, among the SEAPs and MRs, in terms of occurrence, the largest number is related to those sectors supported by a local administration as opposed to private stakeholders. This is highlighted more in the MRs, where sectors such as "Transport" have increased their occurrence fivefold, but in any case, the planned interventions support targeted interventions rather than urban policies.

In the Basilicata case study, the SEAP decisions, according to the principle of subsidiarity, have been taken at the lowest administrative level and closest to the place where each plan produces its effects. Nonetheless, the multi-level governance model included the entire institutional chain: the Basilicata Region, the Provinces and the Municipalities. On the other hand, the full involvement of all the stakeholders (locals, private investors, Small and Medium Enterprises (SMEs), citizen organizations, relevant groups, etc.) of the SEAP process had not come about. Recent studies have also analyzed the "social acceptance" of Renewable Energy developments at an urban level, identifying the trust building process as a way to reduce opposition effects in local communities [43,44]. As a matter of fact, a bottom-up approach including participation in SEAP development was not fully adopted, and from the perspective of the authors, this is the major weakness to overcome in the next GCoM season.

In addition, the Basilicata Region shows how SEAPs, intended as complementary tools in the institutional urban planning framework, and not as alternative ones, effectively support those Municipalities with low numbers of inhabitants or settlements in inland areas to achieve better results in terms of sustainable territorial management based on low-carbon targets: $\mathrm{CO}_{2}$ emission reduction and improvement of the energy efficiency of buildings and industrial processes.

The SEAP experience has introduced in Italy, for the first time, a renewed approach towards voluntary planning; this is particularly relevant for a country that is closely linked to a top-down approach for the development of urban planning.

The forthcoming season of GCoM, characterized by the challenge of climate change, invites signatories to improve their commitments, with a $40 \%$ reduction of $\mathrm{CO}_{2}$ by 2030 and the development of adaptation strategies at an urban scale. This is complementary to the further EU Cohesion Policy (2021/2027) that supports (with relevant funding opportunities) locally led development strategies and empowers local authorities in the management of investments. As a matter of fact, particular care will be given to the urban dimension of the Cohesion Policy, strengthening sustainable urban development with a minimum reserve of $6 \%$ of the ERDF and by a new networking and capacity-building program for urban authorities: the European Urban Initiative.

Additionally, the European Green Deal may represent a horizontal platform for supporting the investments included in the SECAPs and a way to reinforce actions leading to sustainable EU citizenship [45].

The future development of this research will include examining the considerations highlighted, for any critical points of the SEAPs and MRs, so as to extend them to other European adaptation initiatives such as the URBACT and LIFE programs or Integrated Territorial Investments [46] for CoM and non-CoM Municipalities, to develop a decision support system oriented towards the recommendation of strategic adaptation actions [47-49], and taking into account the approaches and the local conditions of the 
Municipalities and the elaboration of performance indicators for the strategies developed [26,50].

The contributions of this work could represent a starting point for a more in-depth evaluation of both the first CoM experience (2008-2015) and the results achieved by the actions included in the SEAP and MRs for every Italian Region, as suggested by the Basilicata Region case study. The knowledge should not stop at the evaluation of the occurrence of the SEAP sectors but should also evaluate the details of the fund expenditures; however, with this paper, we highlight a lack of data in the official CoM sources.

Urban climate adaptation represents a growing trend that includes multiple sectors of investments and generally requires a rethinking of tools and solutions in planning practice: "climate change at an urban scale is creating new ways of understanding and intervening in cities" [51,52].

Author Contributions: Conceptualization, investigation and methodology: L.S. and F.S.; data curation: L.S.; visualization: L.S. and F.S.; writing—review and editing: F.S. All authors have read and agreed to the published version of the manuscript.

Funding: This research received no external funding.

Institutional Review Board Statement: Not applicable.

Informed Consent Statement: Not applicable.

Data Availability Statement: Not applicable.

Conflicts of Interest: The authors declare no conflict of interest.

\section{References}

1. Kern, K.; Bulkeley, H. Cities, Europeanization and Multi-level Governance: Governing Climate Change through Transnational Municipal Networks. JCMS J. Common Mark. Stud. 2009, 47, 309-332. [CrossRef]

2. United Nations Paris Agreement. In Proceedings of the Conference of the Parties on Its Twenty-First Session, France, Paris, 30 November-13 December 2015; p. 32. Available online: https://unfccc.int/resource/docs/2015/cop21/eng/10a01.pdf (accessed on 13 October 2020).

3. European Commission. EUROPE 2020 A Strategy for Smart, Sustainable and Inclusive Growth; Publications Office of the European Union: Brussels, Belgium, 2010.

4. Longo, D.; Boeri, A.; Gianfrate, V.; Palumbo, E.; Boulanger, S.O.M. Resilient cities: Mitigation measures for urban districts. A feasibility study. Int. J. Sustain. Dev. Plan. 2018, 13, 734-745. [CrossRef]

5. Guerrieri, M.; Schibel, K. Mayors Adapt_Diventare Resilienti Localmente in Europa; ISPRA, Stato dell'Ambiente 54/14 ISPRA-Istituto Superiore per la Protezione e la Ricerca Ambientale: Roma, Italy, 2014; pp. 211-218. ISBN 978-88-448-0686-6.

6. Las Casas, G.; Scorza, F.; Murgante, B. New Urban Agenda and Open Challenges for Urban and Regional Planning. In New Metropolitan Perspectives. ISHT 2018; Calabrò, F., Della Spina, L., Bevilacqua, C., Eds.; Springer: Cham, Switzerland, 2019; Volume 100, pp. 282-288. ISBN 9783319920986.

7. Kane, S.; Shogren, J.F. Linking adaptation and mitigation in climate change policy. Clim. Change 2000, 45, 75-102. [CrossRef]

8. Assembly General. United Nations Transforming our world: The 2030 Agenda for Sustainable Development. In Sustainable Development Goals; Wiley: Hoboken, NJ, USA, 2019; pp. 333-374.

9. Pielke, R.A. Misdefining "climate change": Consequences for science and action. Environ. Sci. Policy 2005, 8, 548-561. [CrossRef]

10. Amorim, E.V. Sustainable Energy Action Plans: Project Management Intercomparison. Procedia Technol. 2014, 16, 1183-1189. [CrossRef]

11. Abarca-Alvarez, F.J.; Navarro-Ligero, M.L.; Valenzuela-Montes, L.M.; Campos-Sánchez, F.S. European Strategies for Adaptation to Climate Change With the Mayors Adapt Initiative by Self-Organizing Maps. Appl. Sci. 2019, 9, 3859. [CrossRef]

12. Scorza, F.; Saganeiti, L.; Pilogallo, A.; Murgante, B. Ghost Planning: The inefficiency of energy sector policies in a low population density region. Arch. Stud. Urbani Reg. 2020. [CrossRef]

13. Reckien, D.; Salvia, M.; Heidrich, O.; Church, J.M.; Pietrapertosa, F.; De Gregorio-Hurtado, S.; D'Alonzo, V.; Foley, A.; Simoes, S.G.; Krkoška Lorencová, E.; et al. How are cities planning to respond to climate change? Assessment of local climate plans from 885 cities in the EU-28. J. Clean. Prod. 2018, 191, 207-219. [CrossRef]

14. Aguiar, F.C.; Bentz, J.; Silva, J.M.N.; Fonseca, A.L.; Swart, R.; Santos, F.D.; Penha-Lopes, G. Adaptation to climate change at local level in Europe: An overview. Environ. Sci. Policy 2018, 86, 38-63. [CrossRef]

15. Coelho, S.; Russo, M.; Oliveira, R.; Monteiro, A.; Lopes, M.; Borrego, C. Sustainable energy action plans at city level: A Portuguese experience and perception. J. Clean. Prod. 2018, 176, 1223-1230. [CrossRef] 
16. Klima-Energi-og Bygningsministeriet. Bekendtgørelse af Lov om Varmeforsyning; Klima-Energi-og Forsyningsministeriet: Copenhagen, Denmark, 2014.

17. DKGOV. LOV nr 716 af 25/06/2014: Lov om Klimarådet, Klimapolitisk Redegørelse og Fastsættelse af Nationale Klimamålsætninger; Klima, Energi og Bygningsmin, Energistyrelsen: Copenhagen, Denmark, 2014; j.nr.4001/40010008.

18. List of Ministers of Climate Change-Wikipedia. Available online: https://en.wikipedia.org/wiki/List_of_ministers_of_climate_ change (accessed on 18 November 2020).

19. United Nations. Framework Convention on Climate Change. In Proceedings of the Report of the Conference of the Parties on Its Fifteenth Session, Copenhagen, Denmark, 7-19 December 2009; United Nations: New York, NY, USA, 2009.

20. Malmö Stad. Dagvattenpolicy för Malmö; Malmö Stad: Malmö, Sweden, 2000. (In Swedish)

21. Dall'O', G.; Galante, A.; Sanna, N.; Miller, K. On the Integration of Leadership in Energy and Environmental Design (LEED) ${ }^{\circledR}$ ND Protocol with the Energy Planning and Management Tools in Italy: Strengths and Weaknesses. Energies 2013, 6, 5990-6015. [CrossRef]

22. Covenant of Mayors Plans \& Actions. Available online: https://www.covenantofmayors.eu/plans-and-actions/action-plans. html (accessed on 10 October 2020).

23. International Society of Transport Aircraft Trading. Demo-Geodemo-Mappe, Popolazione, Statistiche Demografiche dell'ISTAT. Available online: http:/ / demo.istat.it/ (accessed on 13 October 2020).

24. Bruno, G. Stato della pianificazione comunale in Basilicata. Urban Inf. 2018, 282, 116.

25. European Commission. Urban Agenda for the EU-Pact of Amsterdam; European Commission: Amsterdam, The Netherlands, 2016.

26. Las Casas, G.; Scorza, F. Sustainable Planning: A Methodological Toolkit. In Lecture Notes in Computer Science (Including Subseries Lecture Notes in Artificial Intelligence and Lecture Notes in Bioinformatics); Springer: Berlin/Heidelberg, Germany, 2016; Volume 9786, pp. 627-635.

27. Santopietro, L.; Faruolo, G.; Scorza, F.; Rossi, A.; Tancredi, M.; Pepe, A.; Giordano, M. Geovisualization for Energy Planning. In Computational Science and Its Applications-ICCSA 2020. ICCSA 2020; Gervasi, O., Murgante, B., Misra, S., Garau, C., Blečić, I., Taniar, D., Apduhan, B.O., Rocha, A.M.A.C., Tarantino, E., Torre, C.M., et al., Eds.; Lecture Notes in Computer Science; Springer: Cham, Switzerland, 2020; Volume 12252. [CrossRef]

28. Laukkonen, J.; Blanco, P.K.; Lenhart, J.; Keiner, M.; Cavric, B.; Kinuthia-Njenga, C. Combining climate change adaptation and mitigation measures at the local level. Habitat. Int. 2009, 33, 287-292. [CrossRef]

29. Priemus, H.; Davoudi, S. Introduction to the Special Issue. Eur. Plan. Stud. 2012, 20, 1-6. [CrossRef]

30. Biesbroek, G.R.; Swart, R.J.; van der Knaap, W.G.M. The mitigation-adaptation dichotomy and the role of spatial planning. Habitat. Int. 2009, 33, 230-237. [CrossRef]

31. Regione Basilicata. Bollettino Ufficiale Della Regione Basilicata n. 47 del 20 Agosto 1999; Regione Basilicata: Potenza, Italy, 1999.

32. Barca, F. An Agenda for a reformed Cohesion policy. A place-based approach to meeting EU Challenges and Expectations; Independent Report to D. Hubner; Commissioner of Regional Policy: Bruxelles, Belgium, 2009.

33. Las Casas, G.; Scorza, F. Comprehensive Evaluation and Context Based Approach for the future of European Regional Operative Programming. In Proceedings of the ERSA 48th European Regional Science Association Congress, Paris, France, 29 August-2 September 2008.

34. Fedeli, V.; Lenzi, C.; Briata, P.; Pedrazzini, L. EU Regional and Urban Policy; Springer Briefs in Applied Sciences and Technology; Springer International Publishing: Cham, Switzerland, 2020; ISBN 978-3-030-34574-7.

35. Dipartimento per le Politiche di Coesione. La Programmazione 2021-2027: Documento Preparatorio per il Confronto Partenariale; Dipartimento per le Politiche di Coesione: Roma, Italy, 2019.

36. Las Casas, G.; Scorza, F.; Murgante, B. Razionalità a-priori: Una proposta verso una pianificazione antifragile. Sci. Reg. 2019, 18, 329-338. [CrossRef]

37. United Nations. New Urban Agenda, Quito, Ecuador; United Nations: New York, NY, USA, 2016; ISBN 978-92-1-132731-1.

38. Comune di Roma Capitale. Piano D'azione per l'Energia Sostenibile (SEAP) Della Città di Roma; Comune di Roma Capitale: Roma, Italy, 2011.

39. Zanon, B. Planning Small Regions in a Larger Europe: Spatial Planning as a Learning Process for Sustainable Local Development. Eur. Plan. Stud. 2010, 18, 2049-2072. [CrossRef]

40. Attolico, A.; Scorza, F. A Transnational Cooperation Perspective for "Low Carbon Economy. In Computational Science and Its Applications-ICCSA 2016. ICCSA 2016; Gervasi, O., Murgante, B., Misra, S., Rocha, A.M.A.C., Torre, C.M., Taniar, D., Apduhan, B.O., Stankova, E., Wang, S., Eds.; Lecture Notes in Computer Science; Springer: Cham, Switzerland, 2016; Volume 9786. [CrossRef]

41. Scorza, F. Towards Self Energy-Management and Sustainable Citizens' Engagement in Local Energy Efficiency Agenda. Int. J. Agric. Environ. Inf. Syst. 2016, 7, 44-53. [CrossRef]

42. Brocchieri, F.; Taurino, E. Stato di Attuazione del Patto dei Sindaci in Italia; Roma, Italy, 2020; ISBN 978-88-448-0988-1. Available online: https:/ / www.isprambiente.gov.it/files2020/pubblicazioni/rapporti/rapporto_316_2020.pdf (accessed on 13 October 2020).

43. Segreto, M.; Principe, L.; Desormeaux, A.; Torre, M.; Tomassetti, L.; Tratzi, P.; Paolini, V.; Petracchini, F. Trends in Social Acceptance of Renewable Energy Across Europe-A Literature Review. Int. J. Environ. Res. Public Health 2020, 17, 9161. [CrossRef] 
44. Wüstenhagen, R.; Wolsink, M.; Bürer, M.J. Social acceptance of renewable energy innovation: An introduction to the concept. Energy Policy 2007, 35, 2683-2691. [CrossRef]

45. European Commission. The European Green Deal; European Commission: Brussels, Belgium, 2020.

46. European Commission. Integrated Territorial Investment. Cohesion Policy 2014-2020; European Commission: Brussels, Belgium, 2014.

47. Dall'O', G.; Norese, M.F.; Galante, A.; Novello, C. A multi-criteria methodology to support public administration decision making concerning sustainable energy action plans. Energies 2013, 6, 4308-4330. [CrossRef]

48. Delponte, I.; Pittaluga, I.; Schenone, C. Monitoring and evaluation of Sustainable Energy Action Plan: Practice and perspective. Energy Policy 2017, 100, 9-17. [CrossRef]

49. Moura, A.C.M.; Campagna, M. Co-design: Digital tools for knowledge-building and decision-making in planning and design. Disegnarecon 2018, 11, ED.1-ED.3.

50. Saganeiti, L.; Pilogallo, A.; Scorza, F.; Mussuto, G.; Murgante, B. Spatial indicators to evaluate urban fragmentation in basilicata region. In Proceedings of the Lecture Notes in Computer Science (Including Subseries Lecture Notes in Artificial Intelligence and Lecture Notes in Bioinformatics); Springer: Cham, Switzerland, 2018; pp. 100-112.

51. Castán Broto, V. Urban Governance and the Politics of Climate change. World Dev. 2017, 93, 1-15. [CrossRef]

52. Castán Broto, V.; Robin, E. Climate urbanism as critical urban theory. Urban Geogr. 2020, 1-6. [CrossRef] 